\title{
A Successful Case of Sural Nerve Cable Grafting after a Gunshot Wound to the Knees
}

\author{
Achal Khanna Ravi Mahajani Timothy Proudman \\ Department of Surgery, Queen Elizabeth Hospital, University of Adelaide, Adelaide, Australia
}

\section{Key Words}

Sural cable graft $\cdot$ Nerve graft $\cdot$ Gunshot wound

\begin{abstract}
Objective: To describe a successful case of sural nerve cable grafting to the leg following a gunshot injury. Clinical Presentation and Intervention: A 28-year-old man was shot at close range, sustaining extensive damage to the left popliteal fossa. Initial exploratory operation revealed a pierced sciatic nerve proximal to its bifurcation into the tibial and common peroneal branches. The $60 \%$ division $3.5-\mathrm{cm}$ common peroneal deficit and the complete transection of the tibial division were repaired using an ipsilateral sural cable nerve graft that was not reversed. Initial re-assessment in the clinic setting revealed a denervation atrophy of all 3 leg compartments and paraesthesia below the left knee sparing the sural nerve. After 3 months, the patient had a significant improvement in both power and sensation which was felt to be due to a resolution of a neuropraxic component to the nerve injury. Re-assessment at 9 months and later at 14 months revealed an almost full recovery, suggestive of the success of the nerve grafting procedure. Conclusion: This report shows that, given favourable conditions, a good result is possible following use of cable nerve grafting to treat nerve damage from gunshot.
\end{abstract}

Copyright (c) 2006 S. Karger AG, Basel

\section{KARGER}

Fax +4161306 1234

E-Mail karger@karger.ch

www.karger.com
(C) 2006 S. Karger AG, Basel

1011-7571/06/0151-0087\$23.50/0

Accessible online at:

www.karger.com/mpp

\section{Introduction}

Firearms were introduced in Europe during the fourteenth century and presented surgeons with a new and challenging form of injury, the gunshot wound. In the fifteenth and sixteenth centuries, it was believed that gunpowder poisoned the wound; bullets were removed, hot oil was placed to neutralize the poison and suppuration was a favourable response. In the mid-sixteenth century, surgeons believed that destruction was solely by disruption of tissue; the practice of primary closure without antibiotics caused very high infection rates. The nineteenth century introduced a new phenomenon, injuries from high-velocity projectiles. The resulting wounds caused extensive hard and soft tissue injuries requiring extensive surgical intervention, techniques of which were refined during World War II. This case report demonstrates that sural nerve cable grafting is a viable treatment modality for a nerve injury that may result from a gunshot wound.

\section{Case Report}

A 28-year-old man was shot at close range $(3 \mathrm{~m})$, with a lowcalibre weapon. The bullet passed through the lateral aspect of the left lower thigh, out through the medial aspect, to become lodged in the right knee.

At presentation to the emergency services, the patient was assessed to be haemodynamically stable, with a wound through the left lower thigh with left medial knee exit wound, and entrance 
Table 1. Muscle power rating at presentation and at 2,9 and 14 months after surgery

\begin{tabular}{lllll}
\hline Muscle & $\begin{array}{l}\text { Presen- } \\
\text { tation }\end{array}$ & $\begin{array}{l}\text { At } \\
2 \text { months }\end{array}$ & $\begin{array}{l}\text { At } \\
9 \text { months }\end{array}$ & $\begin{array}{l}\text { At } \\
14 \text { months }\end{array}$ \\
\hline Gastrocnemius & $0 / 5$ & $0-1 / 5$ & $3 / 5$ & $4-5 / 5$ \\
Plantaris & $0 / 5$ & $0-1 / 5$ & $3 / 5$ & $4-5 / 5$ \\
Soleus & $0 / 5$ & $0-1 / 5$ & $3 / 5$ & $4-5 / 5$ \\
Popliteus & $0 / 5$ & $0 / 5$ & $3 / 5$ & $4-5 / 5$ \\
Tibialis posterior & $0 / 5$ & $0 / 5$ & $3 / 5$ & $4-5 / 5$ \\
Flexor digitorum & $0 / 5$ & $0 / 5$ & $3 / 5$ & $4-5 / 5$ \\
Longus flexor hallucis & $0 / 5$ & $0 / 5$ & $3 / 5$ & $4-5 / 5$ \\
Longus tibialis anterior & $1 / 5$ & $3 / 5$ & $4 / 5$ & $4-5 / 5$ \\
Peroneus tertius & $1 / 5$ & $3 / 5$ & $4 / 5$ & $4-5 / 5$ \\
Peroneus brevis & $0 / 5$ & $2 / 5$ & $3 / 5$ & $4-5 / 5$ \\
Peroneus longus & $0 / 5$ & $2 / 5$ & $3 / 5$ & $4-5 / 5$ \\
Extensor hallucis longus & $1 / 5$ & $3 / 5$ & $4 / 5$ & $4-5 / 5$ \\
Extensor digitorum longus & $0 / 5$ & $0 / 5$ & $4 / 5$ & $4-5 / 5$ \\
\hline
\end{tabular}

wound into the right leg. No vascular injury was present and there were no fractures. However, in addition to the soft tissue wounds, the patient was unable to extend or flex the toes or ankle of the left leg. He was insensate over the dorsum of his foot and first web space. The right leg wound was insignificant. Radiographic examination of both knees showed no bony injury. The bullet was lodged in the right popliteal fossa. The patient was taken to the operating theatre immediately for an exploration of both legs. The exploration of the left leg revealed a pierced sciatic nerve proximal to its bifurcation into the tibial and the common peroneal nerves. On further examination, it was found that the common peroneal nerve was approximately $60 \%$ divided, and the posterior tibial nerve was completely transected. Primary nerve grafting was not entertained at this initial debridement. Exploration of the right leg revealed that the bullet was lodged between the popliteal artery and the sciatic nerve in the popliteal fossa without injury to any major structures. The bullet was removed, and the wounds were debrided and loosely approximated but not closed.

Postoperatively, the patient was managed with intravenous antibiotics, prophylactic doses of clexane, analgesia and was fitted with an ankle-foot orthesis. Upon re-examination it was felt that the patient had a mixed motor and sensory defect similar to the examination findings above.

The patient was re-operated upon 3 days after the initial operation and underwent an ipsilateral sural cable nerve grafting to his left sciatic nerve. The $60 \%$ division of the common peroneal nerve was repaired with 3 grouped fascicles, and the transected posterior tibial nerve with 8 grouped fascicles. The common peroneal deficit was approximately $3.5 \mathrm{~cm}$, and the tibial one was repaired with a nerve segment of $4 \mathrm{~cm}$. Nerves were repaired using a microscope and 9-0 monofilament sutures. The nerve grafts were not reversed. The likelihood of complete recovery was considered to be slight, and this was explained to the patient. Postoperative follow-up included orthotics, physiotherapy and plastic surgery.

Upon review as an out-patient the patient was assessed to have a denervation atrophy of all 3 leg compartments and paraesthesia below the left knee sparing the sural nerve. The patient attended physiotherapy at the hospital twice weekly and performed exercises specifically designed to stretch the affected muscles and nerves and to improve range of movement. He was also fitted with an electrical nerve stimulator to stimulate the denervated muscle groups.

At the initial follow-up the patient had $0 / 5$ muscle power in all muscle groups supplied by the posterior tibial nerve. He was assessed to have a $1 / 5$ power from the tibialis anterior, peroneus tertius and extensor hallucis longus, with the peroneal (lateral) compartment muscles having a $0 / 5$ power rating. The hamstrings were assessed to have a $5 / 5$ power rating. Regarding sensation, the patient described a mild numbness below the knee, with a hypersensitive area on the plantar aspect of his foot. Two months after discharge, the patient had improved power in his anterior tibialis, peroneus tertius and extensor hallucis longus to $3 / 5$. The lateral compartment power increased to $2 / 5$. The recovery was more pronounced in the peroneal nerve than the posterior tibial nerve. Recovery was slight over the initial 3-month period, but he continued with a structured physiotherapy programme. At 3 months, he was able to dorsiflex and plantarflex his ankle against force (power 3/5) but still had no movement in his great toe. At the 9-month review, the patient was re-assessed and found to have an overall improvement in function; he was able to dorsiflex his foot against force $(4 / 5)$ and also plantarflex his foot to $3 / 5$ power. Unfortunately, he had no sensation to the side of his foot. Fourteen months after injury, the patient was felt to have an almost full recovery, being able to both dorsiflex and plantarflex his ankle to $4-5 / 5$ power (table 1 ). However, he did still lack a slight degree of sensation on the lateral aspect of the left side of his foot and the lateral aspect of his calf and leg.

\section{Discussion}

High-velocity injuries produce nerve damage by direct impact, shock waves and cavitation effects [1]. The initial injury dictates the outcome of nerve grafting [2]. In this case there was minimal soft tissue damage sustained, with no bony injury or vascular deficit. This has been shown to have an important influence upon the success of nerve 
grafting. Any longer time period between injury and repair also worsens the outcome. Wietholter et al. [3] showed best results of lingual nerve grafting if reconstruction is performed within 3 weeks of injury. One major factor implicated in poor healing after late grafting repairs is a progressive formation of fibrosis and scar tissue within muscles alongside distal degeneration of the nerve [4]. In addition, muscle degeneration also occurs as early as 34 weeks after injury with a complete replacement of muscle fibres by scar tissue by $2-3$ years [5-7].

Other factors that influence nerve graft success include the rate of revascularisation of the nerve graft, the length of the nerve graft (shorter grafts having the better outcome) and the quality of the repair. The degree of tension on the sutured nerve, the age, general health and nature of injury also influence the outcome after nerve grafts [8]. In this patient, nerve grafts were not reversed. Traditionally it is thought that reversing the polarity of the nerve graft reduces axonal escape. In the rat, reversal of a $1-\mathrm{cm}$ segment of sciatic nerve and subsequent analysis of conduction and amplitude studies have shown no differences when compared to those animals that have had the nerve sutured maintaining polarity [9]. This has been confirmed histologically [10] and electrophysiologically [11].

After 3 months of physiotherapy the patient demonstrated excellent improvements in both power and sensation. Resolution was better in the peroneal nerve when compared to the tibial nerve, perhaps unsurprisingly, bearing in mind the greater degree of injury to the tibial division. The degree of adjacent soft tissue injury was minimal, allowing for nerve grafts to be placed in wellvascularized beds. Time to grafting was short, and the grafting was tension free. The patient may have had a neuropraxic component that resolved, as some of the fascicles of the common peroneal nerve were still intact. Bearing in mind the rapid improvement in muscular function at the 2-month stage, this seems highly likely. Re-examination of the patient at the 14-month stage showed a vast improvement in the function of all affected muscle groups of the leg, indicative of success of the nerve graft procedure.

\section{Conclusion}

This report presents a highly satisfactory clinical outcome to a severe and potentially debilitating injury sustained from a high-velocity traumatic missile. The patient underwent a non-reversed sural nerve cable graft to repair the partial disruption of the common peroneal and transected tibial nerves. This case shows that, given favourable conditions, a good result is possible following early cable nerve grafting, and thus helps to counter a nihilistic attitude towards performance of such repairs. It also demonstrates that, contrary to the consensus of opinion, reversal of nerve grafts before re-anastomosis is not mandatory in order to achieve an excellent recovery.

\section{References}

1 Samardzic M, Rasulic LG, Grujicic DM: Gunshot injuries to the brachial plexus. J Trauma 1997;43:645-649.

-2 Beazley WC, Milek MA, Reiss BH: Results of nerve grafting in severe soft tissue injuries. Clin Orthop Relat Res 1984;188:208-212.

- 3 Wietholter H, Riediger D, Ehrenfeld M, Cornelius CP: Results of microsurgery of sensory peripheral branches of the mandibular nerve. Fortschr Kiefer Gesichtschir 1990;35:128_ 134
4 Narakas A: Indications et résultats du traitement chirurgical direct dans les lésions par élongation du plexus brachial. I. Les indications du traitement chirurgical direct. Rev Chir Orthop Reparatrice Appar Mot 1977;63: 88-106.

5 Kline DG: Macroscopic and microscopic concomitants of nerve repair. Clin Neurosurg 1979;26:582-606.

-6 Kline DG, Judice DJ: Operative management of selected brachial plexus lesions. J Neurosurg 1983;58:631-649.

7 Millesi H: Die chirurgische Behandlung der traumatischen Plexus-brachialis-Läsionen. Orthopäde 1987;16:434-440.
8 Wolford LM, Stevao ELL: Considerations in nerve repair. BUMC Proc 2003;16:152-156.

-9 Stromberg BV, Vlastou C, Earle AS: Effect of nerve graft polarity on nerve regeneration and function. J Hand Surg 1979;4:444-445.

10 Sotereanos DG, Seaber AV, Urbaniak JR, Spiegel DA, Sotereanos D, Anthony DC: Reversing nerve-graft polarity in a rat model: the effect on function. J Reconstr Microsurg 1992; 8:303-307.

11 Nakatsuka H, Takamatsu K, Koshimune M, Imai Y, Enomoto M, Yamano Y: Experimental study of polarity in reversing cable nerve grafts. J Reconstr Microsurg 2002;18:509-515. 